\title{
Extension of WASPAS with Spherical Fuzzy Sets
}

\author{
Fatma KUTLU GUNDOGDU ${ }^{1,2 *}$, Cengiz KAHRAMAN ${ }^{2}$ \\ ${ }^{1}$ Industrial Engineering Department, Istanbul Kültür University, Bakırkoy, \\ Istanbul, 34191, Turkey \\ ${ }^{2}$ Industrial Engineering Department, Istanbul Technical University, Besiktas, \\ Istanbul, 34367, Turkey \\ e-mail:f.kutlu@iku.edu.tr,kahramanc@itu.edu.tr
}

Received: November 2018; accepted: March 2019

\begin{abstract}
The 3D extensions of ordinary fuzzy sets such as intuitionistic fuzzy sets (IFS), Pythagorean fuzzy sets (PFS), and neutrosophic sets (NS) aim to describe experts' judgments more informatively and explicitly. In this paper, generalized three dimensional spherical fuzzy sets are presented with their arithmetic, aggregation, and defuzzification operations. Weighted Aggregated Sum Product ASsessment (WASPAS) is a combination of two well-known multi-criteria decisionmaking (MCDM) methods, which are weighted sum model (WSM) and weighted product model (WPM). The aim of this paper is to extend traditional WASPAS method to spherical fuzzy WASPAS (SF-WASPAS) method and to show its application with an industrial robot selection problem. Additionally, we present comparative and sensitivity analyses to show the validity and robustness of the given decisions.
\end{abstract}

Key words: spherical fuzzy sets, multicriteria decision making, WASPAS, WPM, WSM, spherical distance, industrial robot selection.

\section{Introduction}

WASPAS is the acronym of Weighted Aggregated Sum Product ASsessment method. It is a relatively new method, but it has been widely employed in the literature since its first introduction in 2012 by Zavadskas et al. WASPAS is a weighted combination of Weighted Sum Model (WSM) and Weighted Product Model (WPM) (Zavadskas et al., 2015a, 2015b). Extensions of WASPAS with fuzzy sets such as single-valued neutrosophic sets, interval valued intuitionistic fuzzy sets, and interval type-2 fuzzy sets have been also commonly studied in the literature. The common feature of all these extensions is the usage of linguistic terms including vague and imprecise assessments.

Fuzzy sets have been very popular in almost all branches of science since they have emerged in 1965 (Zadeh, 1965). Researchers (Zadeh, 1965; Smarandache, 1998; Grattan Guinness, 1976; Sambuc, 1975; Zadeh, 1975; Atanassov, 1986; Torra, 2010; Yager, 2013, 1986, 2017; Garibaldi and Ozen, 2007) have introduced many extensions of ordinary fuzzy sets in the literature. It starts from ordinary fuzzy sets and extends to

\footnotetext{
${ }^{*}$ Corresponding author.
} 


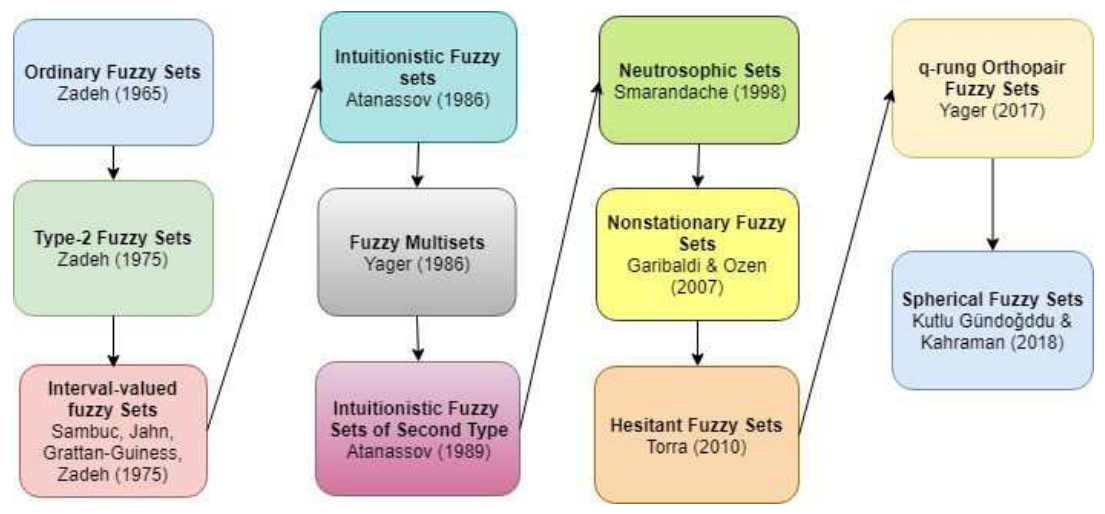

Fig. 1. Extensions of fuzzy sets.

recently developed types of fuzzy sets as shown in Fig. 1. In recent years, numerous researchers have utilized these extensions in the solution of multi-criteria decision-making problems. A classification of some recent publications after 2016 with respect to the type of extension is as follows:

Type-2 fuzzy sets (T2FS): The concept of a type-2 fuzzy set was introduced by Zadeh (1975) as an extension of the concept of an ordinary fuzzy set called a type-1 fuzzy set. Such sets are fuzzy sets whose membership grades themselves are type-1 fuzzy sets; they are very useful in circumstances where it is difficult to determine an exact membership function for a fuzzy set (Cheng et al., 2016; Chiao, 2016).

Intuitionistic fuzzy sets (IFS): Intuitionistic fuzzy sets introduced by Atanassov (1986) enable defining both the membership and non-membership degrees of an element in a fuzzy set (Chen and Chang, 2016; Yu and Xu, 2016; Xu et al., 2016).

Neutrosophic sets (NS): Smarandache (1998) developed neutrosophic logic and neutrosophic sets (NSs) as an extension of intuitionistic fuzzy sets. The neutrosophic set is defined as the set where each element of the universe has a degree of truthfulness, indeterminacy and falsity (Liu, 2016; Ma et al., 2016; Liu et al., 2016).

Hesitant fuzzy sets (HFS): Hesitant fuzzy sets can be used as a functional tool allowing many potential degrees of membership of an element to a set. These fuzzy sets force the membership degree of an element to be possible values between zero and one (Kutlu Gundogdu et al., 2018; Qin et al., 2016; He et al., 2016).

Pythagorean fuzzy sets (PFS): Atanassov's intuitionistic fuzzy sets of second type (IFS2) or Yager's Pythagorean fuzzy sets are characterized by a membership degree and a nonmembership degree satisfying the condition that the square sum of its membership degree and nonmembership degree is equal to or less than one, which is a generalization of Intuitionistic Fuzzy Sets (IFS) (Liu et al., 2017; Garg, 2016; Ren et al., 2016; Peng and Yang, 2016).

qRung orthopair fuzzy sets (qROFs): These sets have been introduced by Yager (2017) as an important way to express uncertain information, and they are an extension of the intuitionistic fuzzy sets and the Pythagorean fuzzy sets. Their eminent characteristic is that the sum of the qth power of the membership degree and the qth power of the degrees of non-membership is equal to or less than 1. 
The spherical fuzzy sets (SFS) have been recently introduced by Kutlu Gundogdu and Kahraman (2018). SFS are based on the fundamentals of PFS and NS. The main differences between q-ROFs and SFS are the definition of hesitancy degree independently in SFS satisfying that the squared sum of membership, non-membership and hesitancy degrees is at most 1 .

Pythagorean fuzzy sets (PFS) developed by Yager (2013), which had been called Intuitionistic type-2 fuzzy sets (IFS2) by Atanassov previously (Atanassov, 1999), are characterized by a membership degree and a nonmembership degree satisfying the condition that their squared sum is at most equal to one, which is a generalization of Intuitionistic Fuzzy Sets (IFS). Hesitancy degree in PFSs calculated by $\pi_{\tilde{p}}=\sqrt{1-\mu_{\tilde{p}}^{2}(u)-v_{\tilde{p}}^{2}(u)}$.

Similar to IFSs and PFSs, neutrosophic sets (NS) are represented by the three dimensions: a truthfulness degree, an indeterminacy degree, and a falsity degree (Smarandache, 1998). NS do not only deal with the hesitancy of the system but also decrease indecisiveness of inconsistent information. Thus, the truthfulness, falsity and indeterminacy values can be independently assigned (Smarandache, 1998).

Yang and Chiclana (2009) have proposed a new 3D spherical representation, which is called the spherical distance and allowed us to define a new distance function between intuitionistic fuzzy sets. On the surface of a sphere, the following condition is satisfied:

Let $\tilde{A}=\left\{\left\langle u, \mu_{\tilde{A}}(u), v_{\tilde{A}}(u)\right\rangle: u \in U\right\}$ be an intuitionistic fuzzy set. They have

$$
\mu_{\tilde{A}}+v_{\tilde{A}}+\pi_{\tilde{A}}=1,
$$

which can be equivalently transformed to

$$
x^{2}+y^{2}+z^{2}=1
$$

where $x^{2}=\mu_{\tilde{A}}(u), y^{2}=v_{\tilde{A}}(u), z^{2}=\pi_{\tilde{A}}(u)$.

On a spherical surface, hesitancy can be calculated based on the given membership and non-membership values since the sum of these three parameters is exactly equal to 1 (Yang and Chiclana, 2009). Besides, they measure the spherical arc distance between two IFSs. Furthermore, Gong et al. (2016) introduced an approach generalizing Yang and Chiclana's work. They applied the spherical distance measure to obtain the difference between two IFSs. They first introduced an ideal intuitionistic fuzzy estimation, and then by minimizing the spherical distance between the ideal opinion and each individual opinion in group decisions, they constructed a nonlinear optimization model.

The spherical fuzzy sets are based on the fact that the hesitancy of a decision maker can be assigned independently from membership and non-membership degrees, satisfying the following condition:

$$
\tilde{A}_{s}=\left\{\left\langle u,\left(\mu_{\tilde{A}}(u), v_{\tilde{A}}(u), \pi_{\tilde{A}}(u)\right\rangle\right| u \in U\right\},
$$

where $\mu_{\tilde{A}_{s}}: U \rightarrow[0,1], v_{\tilde{A}_{s}}: U \rightarrow[0,1], \pi_{\tilde{A}_{s}}: U \rightarrow[0,1]$ and $0 \leqslant \mu_{\tilde{A}_{s}}^{2}(u)+v_{\tilde{A}_{s}}^{2}(u)+$ $\pi_{\tilde{A}_{s}}^{2}(u) \leqslant 1, \forall u \in U$. 


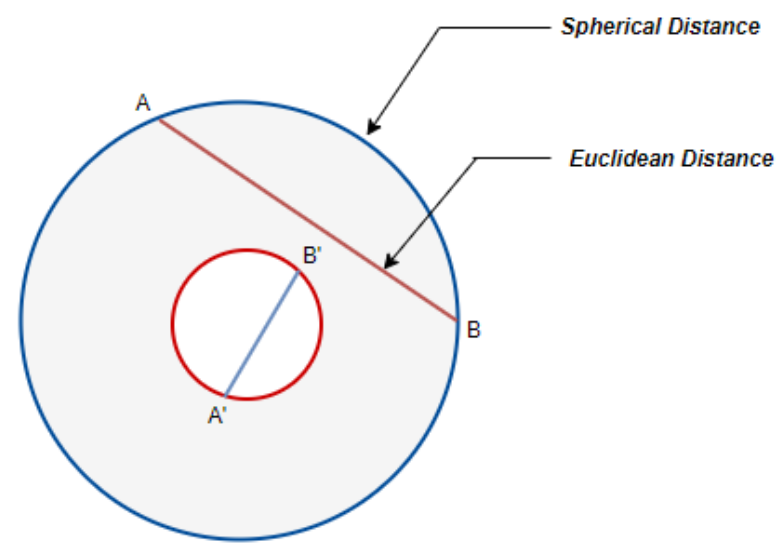

Fig. 2. Euclidean and spherical distances.

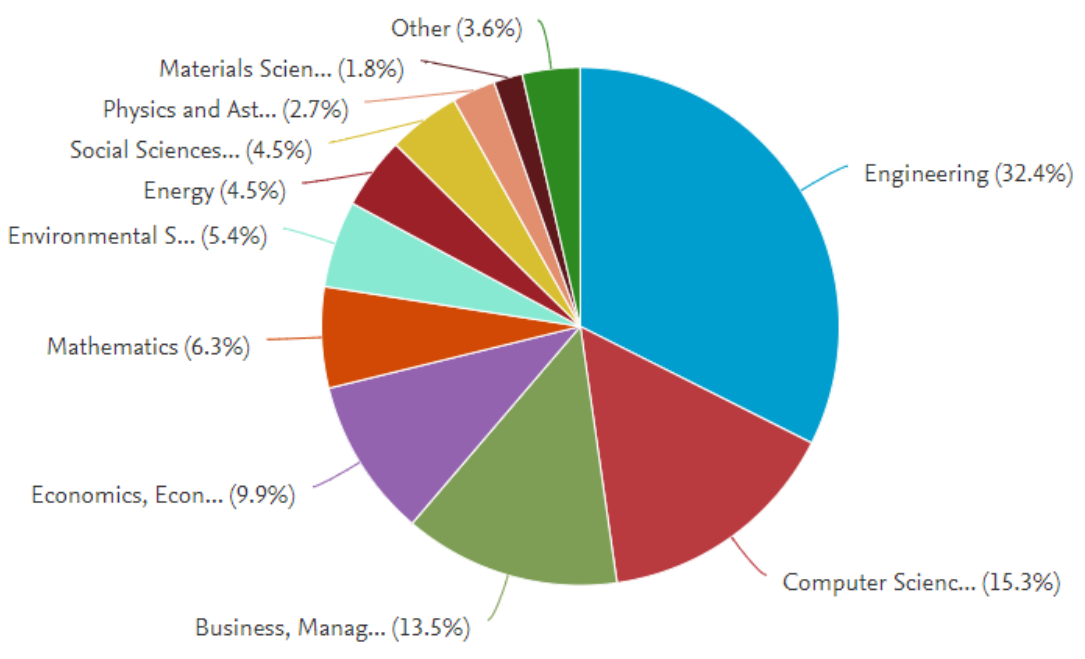

Fig. 3. Subject areas of the WASPAS papers.

On the surface of the blue coloured sphere in Fig. 2, Eq. (3) becomes

$$
\mu_{\tilde{A}}^{2}(u)+v_{\tilde{A}}^{2}(u)+\pi_{\tilde{A}}^{2}(u)=1 .
$$

Since Yang and Chiclana (2009) and Gong et al. (2016) only measure the arc distances on the surface of the sphere, Euclidean distance is not measured in these works. In our spherical fuzzy sets approach, the sphere is not solid but a spherical volume. Based on this fact, Euclidean distance measurement is meaningful. This also means that any two points within the spherical volume are also on the surface of another sphere; however, the sum given by Eq. (4) becomes less than one in this case (red coloured sphere in Fig. 3). Euclidean distance gives the shortest distance between two points in the space as in Fig. 2. 
In this paper, we extend one of the most used multi-criteria decision making methods, WASPAS, to its spherical fuzzy version. We illustrate its application through an industrial robot selection problem.

The rest of this paper is organized as follows. Section 2 includes the literature review on WASPAS. Section 3 gives introductory definitions on 3D fuzzy sets. In Section 4, the preliminaries on SFS are given. Section 5 includes our novel proposed MCDM method called Spherical Fuzzy WASPAS method (SF-WASPAS) and Section 6 applies SF-WASPAS method to industrial robot selection problem and also includes a comparative analysis of SF-WASPAS and IF-TOPSIS. Finally, the last section presents the conclusions and suggestions for further research.

\section{Literature Review on WASPAS}

The publications on WASPAS method are summarized in Table 1.

In Fig. 3, the subject areas of the papers on WASPAS method are illustrated. Engineering applications is the top area with $32.4 \%$ while computer science and businessmanagement place at the second and third ranks, respectively.

\section{3D Fuzzy Sets}

Since spherical fuzzy sets are the extension of IFS, PFS and NS, we briefly summarize these sets in the following.

\subsection{Intuitionistic Fuzzy Sets (IFS)}

Let $U$ be a universe of discourse. An IFS $\tilde{A}$ is an object having the form,

$$
\tilde{A}=\left\{\left\langle u,\left(\mu_{\tilde{A}}(u), v_{\tilde{A}}(u)\right)\right\rangle \mid u \in U\right\},
$$

where $\mu_{\tilde{A}}: U \rightarrow[0,1], v_{\tilde{A}}: U \rightarrow[0,1]$, and $0 \leqslant \mu_{\tilde{A}}(u)+v_{\tilde{A}}(u) \leqslant 1$ are the degree of membership, non-membership of $u$ to $\tilde{A}$, respectively. to $\tilde{A}$.

For any IFS $\tilde{A}$ and $u \in U, \pi_{\tilde{A}}=1-\mu_{\tilde{A}}(u)-v_{\tilde{A}}(u)$ is called degree of hesitancy of $u$

In order to present a larger preference area to decision makers (DMs), Yager (2013) proposed a novel concept called PFS (Pythagorean Fuzzy Sets).

\subsection{Pythagorean Fuzzy Sets (PFS)}

Let $U$ be a universe of discourse. A PFS $\tilde{P}$ is an object having the form,

$$
\tilde{P}=\left\{\left\langle u,\left(\mu_{\tilde{P}}(u), v_{\tilde{P}}(u)\right)\right\rangle \mid u \in U\right\},
$$


Table 1

A literature review on WASPAS.

\begin{tabular}{|c|c|c|c|}
\hline Year & Authors & $\begin{array}{l}\text { Extension of } \\
\text { WASPAS }\end{array}$ & Application area \\
\hline 2012 & Zavadskas et al. & Crisp & Illustrative example \\
\hline 2013 & Dejus and Antucheviciene & Crisp & $\begin{array}{l}\text { Assessment of suitable solutions for } \\
\text { occupational safety }\end{array}$ \\
\hline 2014 & Chakraborty and Zavadskas & Crisp & $\begin{array}{l}\text { Selection of cutting fluid, electroplating } \\
\text { system, forging condition, arc welding } \\
\text { process, industrial robot (Manufacturing } \\
\text { decision process) }\end{array}$ \\
\hline 2014 & Lashgari et al. & Crisp & Evaluation of outsourcing strategies \\
\hline 2014 & Vafaeipour et al. & Crisp & Site selection of solar power plants \\
\hline 2014 & Zavadskas et al. & $\begin{array}{l}\text { Interval-valued } \\
\text { intuitionistic } \\
\text { fuzzy numbers }\end{array}$ & $\begin{array}{l}\text { Numerical examples of ranking derelict } \\
\text { buildings' redevelopment decisions and } \\
\text { investment alternatives }\end{array}$ \\
\hline 2015 & Zavadskas et al. & Crisp & Optimal indoor environment selection \\
\hline 2015 & Zavadskas et al. & Crisp & Illustrative examples \\
\hline 2015 & Turskis et al. & Fuzzy & Construction site selection \\
\hline 2016 & Keshavarz Ghorabaee et al. & $\begin{array}{l}\text { Interval type-2 } \\
\text { fuzzy sets }\end{array}$ & Green suppliers evaluation \\
\hline 2017 & Nie et al. & $\begin{array}{l}\text { Interval } \\
\text { neutrosophic sets }\end{array}$ & Solar-wind power station site selection \\
\hline 2017 & Bausys and Juodagalviene & $\begin{array}{l}\text { Single-valued } \\
\text { neutrosophic set }\end{array}$ & Garage location selection \\
\hline 2017 & Keshavarz Ghorabaee et al. & $\begin{array}{l}\text { Interval type-2 } \\
\text { fuzzy sets }\end{array}$ & $\begin{array}{l}\text { Assessment of third-party logistics } \\
\text { providers }\end{array}$ \\
\hline 2017 & Peng and Dai & $\begin{array}{l}\text { Hesitant fuzzy } \\
\text { soft decision } \\
\text { making }\end{array}$ & Illustrative examples \\
\hline 2018 & Stojic et al. & Rough WASPAS & $\begin{array}{l}\text { Selection in a Company Manufacturing } \\
\text { PVC Carpentry Products }\end{array}$ \\
\hline 2018 & Hafezalkotob et al. & $\begin{array}{l}\text { Target Based } \\
\text { WASPAS } \\
\text { (T-WASPAS) }\end{array}$ & Selection of agricultural machines \\
\hline 2018 & Can & $\begin{array}{l}\text { Intuitionistic } \\
\text { FMEAWASPAS } \\
\text { approach }\end{array}$ & Illustrative examples \\
\hline 2018 & Mishra et al. & $\begin{array}{l}\text { Intuitionistic } \\
\text { fuzzy WASPAS }\end{array}$ & $\begin{array}{l}\text { Assessment of cellular mobile telephone } \\
\text { service providers }\end{array}$ \\
\hline 2018 & Jahan & $\begin{array}{l}\text { WASPAS-Range } \\
\text { Target Based } \\
\text { (RTB) }\end{array}$ & Protective coating material selection \\
\hline 2018 & Stevic et al. & Rough WASPAS & $\begin{array}{l}\text { Location selection for roundabout } \\
\text { construction }\end{array}$ \\
\hline 2018 & Chen et al. & $\begin{array}{l}\text { WASPAS with } \\
\text { normalization } \\
\text { (WASPAS-N) }\end{array}$ & Selection of a Teahouse Location \\
\hline
\end{tabular}


where $\mu_{\tilde{P}}: U \rightarrow[0,1], v_{\tilde{P}}: U \rightarrow[0,1]$, and $0 \leqslant \mu_{\tilde{P}}^{2}(u)+v_{\tilde{P}}^{2}(u) \leqslant 1$ are the degree of membership, non-membership of $u$ to $\tilde{P}$, respectively.

For any PFS $\tilde{P}$ and $u \in U, \pi_{\tilde{P}}=\left(1-\mu_{\tilde{P}}^{2}(u)-v_{\tilde{P}}^{2}(u)\right)^{1 / 2}$ is called degree of hesitancy of $u$ to $\tilde{P}$.

\subsection{Neutrosophic Sets}

Let $U$ be a universe of discourse. Neutrosophic set $\tilde{A}$ in $U$ is an object having the form,

$$
\tilde{A}=\left\{\left\langle u,\left(T_{\tilde{A}}(u), I_{\tilde{A}}(u), F_{\tilde{A}}(u)\right)\right\rangle \mid u \in U\right\},
$$

where $T_{\tilde{A}}$ is the truth-membership function, $I_{\tilde{A}}$ is the indeterminacy-membership function and $F_{\tilde{A}}$ is the falsity-membership function. There is no restriction on their sum and so

$$
0 \leqslant T_{\tilde{A}}(u)+I_{\tilde{A}}(u)+F_{\tilde{A}}(u) \leqslant 3 .
$$

In the following, we introduce a novel concept of SFS (Spherical Fuzzy Sets), which provides a larger preference domain for decision makers. DMs can also define their hesitancy information of an alternative with respect to a criterion independently.

\section{Spherical Fuzzy Sets: Preliminaries}

Intuitionistic and Pythagorean fuzzy membership functions are composed of membership, non-membership and hesitancy parameters, which can be calculated by $\pi_{\tilde{I}}=1-\mu-v$ or $\pi_{\tilde{P}}=\sqrt{1-\mu^{2}-v^{2}}$, respectively. Neutrosophic membership functions are also defined by three parameters truthfulness, falsity and indeterminacy, whose sum can be between 0 and 3, and the value of each is between 0 and 1 independently. In spherical fuzzy sets, while the squared sum of membership, non-membership and hesitancy parameters can be between 0 and 1 , each of them can be defined between 0 and 1 independently to satisfy that their squared sum is at most equal to 1 . Figure 4 illustrates the differences among IFS, PFS, NS and SFS.

In this section, we give the definition of SFS and summarize spherical distance measurement, arithmetic operations, aggregation and defuzzification operations (Kutlu Gundogdu and Kahraman, 2018).

Definition 1. Spherical Fuzzy Sets (SFS) $\tilde{A}_{S}$ of the universe of discourse $U$ is given by

$$
\tilde{A}_{s}=\left\{\left\langle u,\left(\mu_{\tilde{A}_{s}}(u), v_{\tilde{A}_{s}}(u), \pi_{\tilde{A}_{s}}(u)\right)\right\rangle \mid u \in U\right\}
$$

where $\mu_{\tilde{A}_{s}}: U \rightarrow[0,1], v_{\tilde{A}_{s}}: U \rightarrow[0,1], \pi_{\tilde{A}_{s}}: U \rightarrow[0,1]$ and

$$
0 \leqslant \mu_{\tilde{A}_{s}}^{2}(u)+v_{\tilde{A}_{s}}^{2}(u)+\pi_{\tilde{A}_{s}}^{2}(u) \leqslant 1 \quad \forall u \in U
$$




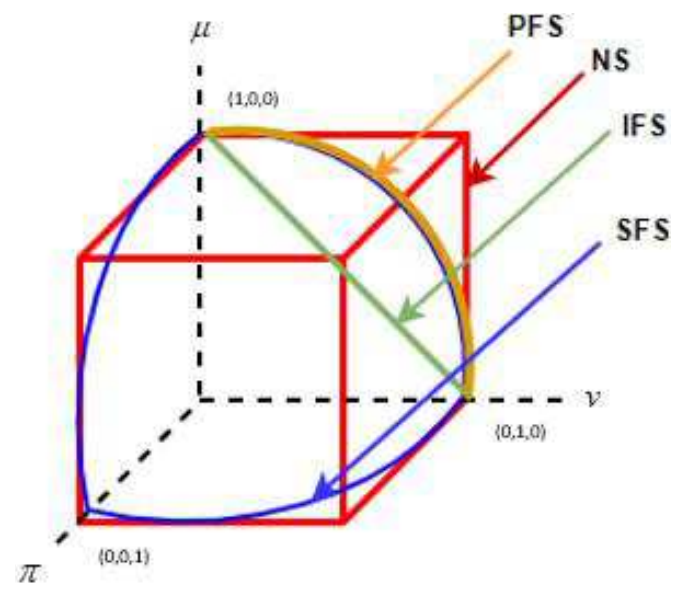

Fig. 4. Geometric representations of IFS, PFS, NS and SFS.

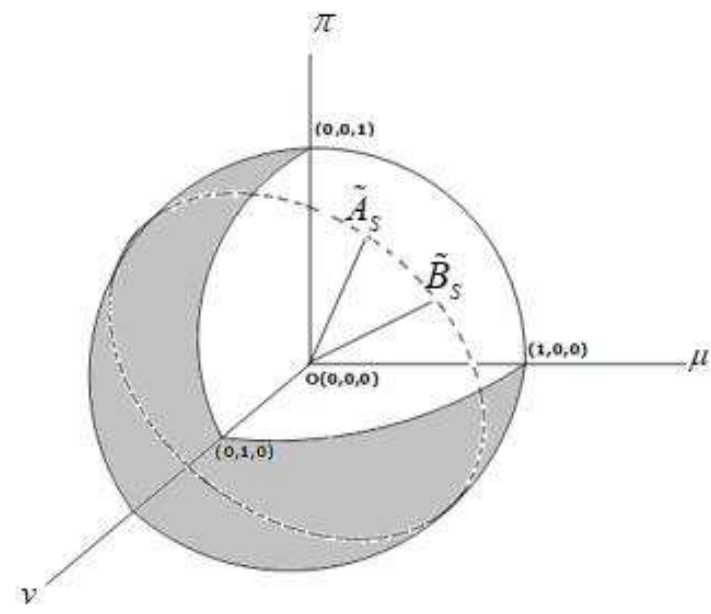

Fig. 5. Geometrical representation of spherical fuzzy sets.

For each $u$, the numbers $\mu_{\tilde{A}_{s}}(u), v_{\tilde{A}_{s}}(u)$ and $\pi_{\tilde{A}_{s}}(u)$ are degree of membership, nonmembership and hesitancy of $u$ to $\tilde{A}_{s}$, respectively. Geometrical representation of SFS is given in Fig. 5 (Yang and Chiclana, 2009).

Some operations are defined over the Spherical Fuzzy Sets (SFS) as below.

On the basis of relationship between SFS and PFS, we further define some novel operations for SFS as below:

Definition 2. Basic Operators

\section{Union:}

$$
\begin{aligned}
\tilde{A}_{s} \cup \tilde{B}_{s}= & \left\langle\max \left\{\mu_{\tilde{A}_{s}}, \mu_{\tilde{B}_{s}}\right\}, \min \left\{v_{\tilde{A}_{s}}, v_{\tilde{B}_{s}}\right\}, \max \left\{1-\left(\left(\max \left\{\mu_{\tilde{A}_{s}}, \mu_{\tilde{B}_{s}}\right\}\right)^{2}\right.\right.\right. \\
& \left.\left.+\left(\min \left\{v_{\tilde{A}_{s}}, v_{\tilde{B}_{s}}\right\}\right)^{2}\right), \max \left\{\pi_{\tilde{A}_{s}}, \pi_{\tilde{B}_{s}}\right\}\right\} .
\end{aligned}
$$




\section{Intersection:}

$$
\begin{aligned}
\tilde{A}_{s} \cap \tilde{B}_{s}= & \left\langle\min \left\{\mu_{\tilde{A}_{s}}, \mu_{\tilde{B}_{s}}\right\}, \max \left\{v_{\tilde{A}_{s}}, v_{\tilde{B}_{s}}\right\}, \min \left\{1-\left(\left(\min \left\{\mu_{\tilde{A}_{s}}, \mu_{\tilde{B}_{s}}\right\}\right)^{2}\right.\right.\right. \\
& \left.\left.+\left(\max \left\{v_{\tilde{A}_{s}}, v_{\tilde{B}_{s}}\right\}\right)^{2}\right), \min \left\{\pi_{\tilde{A}_{s}}, \pi_{\tilde{B}_{s}}\right\}\right\rangle .
\end{aligned}
$$

\section{Addition:}

$$
\begin{aligned}
\tilde{A}_{s} \oplus \tilde{B}_{s}= & \left\langle\left(\mu_{\tilde{A}_{s}}^{2}+\mu_{\tilde{B}_{s}}^{2}-\mu_{\tilde{A}_{s}}^{2} \mu_{\tilde{B}_{s}}^{2}\right)^{1 / 2}, v_{\tilde{A}_{s}} v_{\tilde{B}_{s}},\left(\left(1-\mu_{\tilde{B}_{s}}^{2}\right) \pi_{\tilde{A}_{s}}^{2}\right.\right. \\
& \left.\left.+\left(1-\mu_{\tilde{A}_{s}}^{2}\right) \pi_{\tilde{B}_{s}}^{2}-\pi_{\tilde{A}_{s}}^{2} \pi_{\tilde{B}_{s}}^{2}\right)^{1 / 2}\right\rangle .
\end{aligned}
$$

\section{Multiplication:}

$$
\begin{aligned}
\tilde{A}_{s} \otimes \tilde{B}_{s}= & \left\langle\mu_{\tilde{A}_{s}} \mu_{\tilde{B}_{s}},\left(v_{\tilde{A}_{s}}^{2}+v_{\tilde{B}_{s}}^{2}-v_{\tilde{A}_{s}}^{2} v_{\tilde{B}_{s}}^{2}\right)^{1 / 2},\left(\left(1-v_{\tilde{B}_{s}}^{2}\right) \pi_{\tilde{A}_{s}}^{2}\right.\right. \\
& \left.\left.+\left(1-v_{\tilde{A}_{s}}^{2}\right) \pi_{\tilde{B}_{s}}^{2}-\pi_{\tilde{A}_{s}}^{2} \pi_{\tilde{B}_{s}}^{2}\right)^{1 / 2}\right\rangle .
\end{aligned}
$$

Multiplication by a scalar: $\lambda>0$

$$
\lambda \tilde{A}_{s}=\left\langle\left(1-\left(1-\mu_{\tilde{A}_{s}}^{2}\right)^{\lambda}\right)^{1 / 2}, v_{\tilde{A}_{s}}^{\lambda},\left(\left(1-\mu_{\tilde{A}_{s}}^{2}\right)^{\lambda}-\left(1-\mu_{\tilde{A}_{s}}^{2}-\pi_{\tilde{A}_{s}}^{2}\right)^{\lambda}\right)^{1 / 2}\right\rangle .
$$

$\lambda$ th power of $\tilde{A}_{s} ; \lambda>0$

$$
\tilde{A}_{s}^{\lambda}=\left\langle\mu_{\tilde{A}_{s}}^{\lambda},\left(1-\left(1-v_{\tilde{A}_{s}}^{2}\right)^{\lambda}\right)^{1 / 2},\left(\left(1-v_{\tilde{A}_{s}}^{2}\right)^{\lambda}-\left(1-v_{\tilde{A}_{s}}^{2}-\pi_{\tilde{A}_{s}}^{2}\right)^{\lambda}\right)^{1 / 2}\right\rangle .
$$

Definition 3. For these SFS $\tilde{A}_{s}=\left(\mu_{\tilde{A}_{s}}, v_{\tilde{A}_{s}}, \pi_{\tilde{A}_{s}}\right)$ and $\tilde{B}_{S}=\left(\mu_{\tilde{B}_{s}}, v_{\tilde{B}_{s}}, \pi_{\tilde{B}_{s}}\right)$, the followings are valid under the condition $\lambda, \lambda_{1}, \lambda_{2}>0$.

$$
\begin{aligned}
& \tilde{A}_{s} \oplus \tilde{B}_{s}=\tilde{B}_{s} \oplus \tilde{A}_{s}, \\
& \tilde{A}_{s} \otimes \tilde{B}_{s}=\tilde{B}_{s} \otimes \tilde{A}_{s}, \\
& \lambda\left(\tilde{A}_{s} \oplus \tilde{B}_{s}\right)=\lambda \tilde{A}_{s} \oplus \lambda \tilde{B}_{s}, \\
& \lambda_{1} \tilde{A}_{s} \oplus \lambda_{2} \tilde{A}_{s}=\left(\lambda_{1}+\lambda_{2}\right) \tilde{A}_{s}, \\
& \left(\tilde{A}_{s} \otimes \tilde{B}_{s}\right)^{\lambda}=\tilde{A}_{s}^{\lambda} \otimes \tilde{B}_{s}^{\lambda}, \\
& \tilde{A}_{s}^{\lambda_{1}} \otimes \tilde{A}_{s}^{\lambda_{2}}=\tilde{A}_{s}^{\lambda_{1}+\lambda_{2}} .
\end{aligned}
$$

Proofs of the above equations can be found in Kutlu Gundogdu and Kahraman (2018).

Definition 4. Spherical Weighted Arithmetic Mean (SWAM) with respect to $w=$ $\left(w_{1}, w_{2}, \ldots, w_{n}\right), w_{i} \in[0,1] ; \sum_{i=1}^{n} w_{i}=1$, SWAM is defined as: 


$$
\begin{aligned}
\operatorname{SWAM}_{w}\left(\tilde{A}_{s 1}, \tilde{A}_{s 2}, \ldots, \tilde{A}_{s n}\right)= & w_{1} \tilde{A}_{s 1}+w_{2} \tilde{A}_{s 2}+\cdots+w_{n} \tilde{A}_{s n} \\
= & \left\langle\left[1-\prod_{i=1}^{n}\left(1-\mu_{\tilde{A}_{s i}}^{2}\right)^{w_{i}}\right]^{1 / 2}, \prod_{i=1}^{n} v_{\tilde{A}_{s i}}^{w_{i}},\right. \\
& {\left.\left[\prod_{i=1}^{n}\left(1-\mu_{\tilde{A}_{s i}}^{2}\right)^{w_{i}}-\prod_{i=1}^{n}\left(1-\mu_{\tilde{A}_{s i}}^{2}-\pi_{\tilde{A}_{s i}}^{2}\right)^{w_{i}}\right]^{1 / 2}\right\rangle . }
\end{aligned}
$$

Definition 5. Spherical Weighted Geometric Mean (SWGM) with respect to $w=$ $\left(w_{1}, w_{2}, \ldots, w_{n}\right), w_{i} \in[0,1] ; \sum_{i=1}^{n} w_{i}=1$, SWGM is defined as:

$$
\begin{aligned}
\operatorname{SWGM}_{w}\left(\tilde{A}_{s 1}, \tilde{A}_{s 2}, \ldots, \tilde{A}_{s n}\right)= & \tilde{A}_{s 1}^{w_{1}}+\tilde{A}_{s 2}^{w_{2}}+\cdots+\tilde{A}_{s n}^{w_{n}} \\
= & \left\langle\prod_{i=1}^{n} \mu_{\tilde{A}_{s i}}^{w_{i}},\left[1-\prod_{i=1}^{n}\left(1-v_{\tilde{A}_{s i}}^{2}\right)^{w_{i}}\right]^{1 / 2},\right. \\
& {\left.\left[\prod_{i=1}^{n}\left(1-v_{\tilde{A}_{s i}}^{2}\right)^{w_{i}}-\prod_{i=1}^{n}\left(1-v_{\tilde{A}_{s i}}^{2}-\pi_{\tilde{A}_{s i}}^{2}\right)^{w_{i}}\right]^{1 / 2}\right\rangle . }
\end{aligned}
$$

Definition 6. Score function and Accuracy function of sorting SFS are defined by

$$
\begin{aligned}
& \operatorname{Score}\left(\tilde{A}_{s}\right)=\left(\mu_{A_{s}}-\pi_{A_{s}}\right)^{2}-\left(v_{A_{s}}-\pi_{A_{s}}\right)^{2}, \\
& \operatorname{Accuracy}\left(\tilde{A}_{s}\right)=\mu_{A_{s}}^{2}+v_{A_{s}}^{2}+\pi_{A_{s}}^{2} .
\end{aligned}
$$

Note that: $\tilde{A}_{s}<B_{s}$ if and only if $\operatorname{Score}\left(\tilde{A}_{s}\right)<\operatorname{Score}\left(\tilde{B}_{S}\right)$ or $\operatorname{Score}\left(\tilde{A}_{s}\right)=\operatorname{Score}\left(\tilde{B}_{S}\right)$ and $\operatorname{Accuracy}\left(\tilde{A}_{S}\right)<\operatorname{Accuracy}\left(\tilde{B}_{S}\right)$.

\section{Extension of WASPAS with Spherical Fuzzy Sets}

A MCDM problem can be expressed as a decision matrix whose elements indicate the evaluation values of all alternatives with respect to each criterion under Spherical fuzzy environment. Let $X=\left\{x_{1}, x_{2}, \ldots, x_{m}\right\}(m \geqslant 2)$ be a discrete set of $m$ feasible alternatives and $C=\left\{c_{1}, c_{2}, \ldots, c_{n}\right\}$ be a finite set of criteria and $W=\left\{w_{1}, w_{2}, \ldots, w_{n}\right\}$ be the weight vector of all criteria which satisfies $0 \leqslant w_{j} \leqslant 1$ and $\sum_{j=1}^{n} w_{j}=1$.

The proposed spherical fuzzy WASPAS method is composed of several steps as given in this section. Before giving these steps, we present the flow chart of the SF-WASPAS method in Fig. 6 in order to make it easily understandable.

Step 1: Let DMs fill in the decision and criteria evaluation matrices using the linguistic terms given in Table 2. 


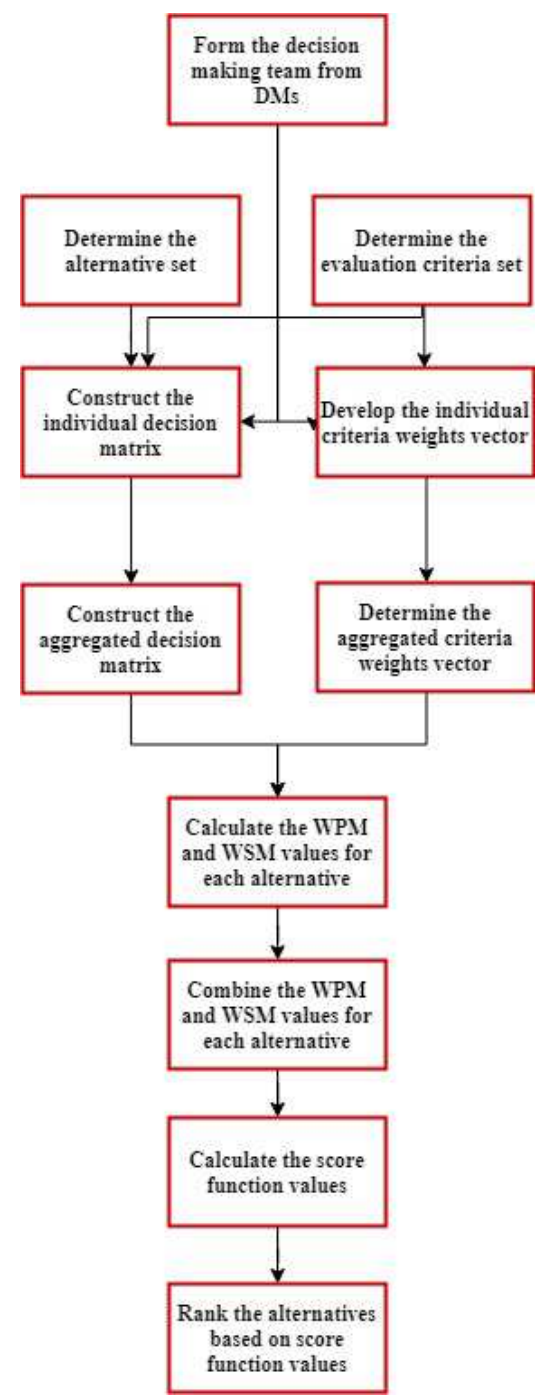

Fig. 6. SF-WASPAS proposed methodology.

Table 2

Linguistic terms and their corresponding spherical fuzzy numbers.

\begin{tabular}{ll}
\hline & $(\mu, \nu, \pi)$ \\
\hline Absolutely More Importance (AMI) & $(0.9,0.1,0.1)$ \\
Very High Importance (VHI) & $(0.8,0.2,0.2)$ \\
High Importance (HI) & $(0.7,0.3,0.3)$ \\
Slightly More Importance (SMI) & $(0.6,0.4,0.4)$ \\
Equally Importance (EI) & $(0.5,0.5,0.5)$ \\
Slightly Low Importance (SLI) & $(0.4,0.6,0.4)$ \\
Low Importance (LI) & $(0.3,0.7,0.3)$ \\
Very Low Importance (VLI) & $(0.2,0.8,0.2)$ \\
Absolutely Low Importance (ALI) & $(0.1,0.9,0.1)$ \\
\hline
\end{tabular}


Table 3

Evaluation of criteria by DMs.

\begin{tabular}{lllll}
\hline Criteria & DM1 & DM2 & $\ldots$ & DMk \\
\hline $\mathrm{C} 1$ & $\left(\mu_{11}, v_{11}, \pi_{11}\right)$ & $\left(\mu_{12}, v_{12}, \pi_{12}\right)$ & $\ldots$ & $\left(\mu_{1 k}, v_{1 k}, \pi_{1 k}\right)$ \\
$\mathrm{C} 2$ & $\left(\mu_{21}, v_{21}, \pi_{21}\right)$ & $\left(\mu_{22}, v_{22}, \pi_{22}\right)$ & $\ldots$ & $\left(\mu_{2 k}, v_{2 k}, \pi_{2 k}\right)$ \\
$\vdots$ & $\vdots$ & $\vdots$ & $\ddots$ & $\vdots$ \\
$\mathrm{Cj}$ & $\left(\mu_{j 1}, v_{j 1}, \pi_{j 1}\right)$ & $\left(\mu_{j 2}, v_{j 2}, \pi_{j 2}\right)$ & $\ldots$ & $\left(\mu_{j k}, v_{j k}, \pi_{j k}\right)$ \\
\hline
\end{tabular}

Step 2: Aggregate the judgments of each decision maker (DM) using Spherical Weighted Arithmetic Mean (SWAM).

$$
\begin{aligned}
\operatorname{SWAM}_{w}\left(A_{s 1}, A_{s 2}, \ldots, A_{s n}\right)= & w_{1} A_{s 1}+w_{2} A_{s 2}+\cdots+w_{n} A_{s n} \\
= & \left\langle\left[1-\prod_{i=1}^{n}\left(1-\mu_{A_{s i}}^{2}\right)^{w_{i}}\right]^{1 / 2}, \prod_{i=1}^{n} v_{A_{s i}}^{w_{i}},\right. \\
& {\left.\left[\prod_{i=1}^{n}\left(1-\mu_{A_{s i}}^{2}\right)^{w_{i}}-\prod_{i=1}^{n}\left(1-\mu_{A_{s i}}^{2}-\pi_{A_{s i}}^{2}\right)^{w_{i}}\right]^{1 / 2}\right\rangle . }
\end{aligned}
$$

Step 2.1: Aggregate the criteria weights. All criteria may not be assumed to be of equal importance. In order to obtain weights, all the individual decision maker opinions for the importance of each criterion need to be aggregated.

Step 2.2: Construct aggregated spherical fuzzy decision matrix based on the opinions of decision makers. Denote the evaluation values of alternative $x_{i}(1,2, \ldots, m)$ with respect to criterion $C_{j}(1,2, \ldots, n)$ by $C_{j}\left(\tilde{x}_{i}\right)=\left(\mu_{i j}, v_{i j}, \pi_{i j}\right)$ and $\tilde{x}_{i j}=\left(C_{j}\left(\tilde{x}_{i}\right)\right)_{m \times n}$ is a spherical fuzzy decision matrix. For a MCDM problem with SFS, decision matrix $\tilde{x}_{i j}=\left(C_{j}\left(\tilde{x}_{i}\right)\right)_{m \times n}$ should be constructed as in Eq. (28).

$$
\begin{aligned}
\tilde{x}_{i j}= & \left(C_{j}\left(\tilde{x}_{i}\right)\right)_{m \times n} \\
= & \left(\begin{array}{cccc}
\left(\mu_{11}, v_{11}, \pi_{11}\right) & \left(\mu_{12}, v_{12}, \pi_{12}\right) & \ldots & \left(\mu_{1 n}, v_{1 n}, \pi_{1 n}\right) \\
\left(\mu_{21}, v_{21}, \pi_{21}\right) & \left(\mu_{22}, v_{22}, \pi_{22}\right) & \ldots & \left(\mu_{2 n}, v_{2 n}, \pi_{2 n}\right) \\
\vdots & \vdots & \ddots & \vdots \\
\left(\mu_{m 1}, v_{m 1}, \pi_{m 1}\right) & \left(\mu_{m 2}, v_{m 2}, \pi_{m 2}\right) & \ldots & \left(\mu_{m n}, v_{m n}, \pi_{m n}\right)
\end{array}\right) .
\end{aligned}
$$

Decision makers also evaluate the decision criteria as given in Table 3.

Decision makers assess the alternatives with respect to the criteria as if they were benefit criteria such that they assign a lower linguistic term if it is a cost criterion.

Step 3: Calculate the score function value of each criterion in Table 3 and then normalize these values. 
Step 3.1: Defuzzify the aggregated criteria weights by using the score function given in Eq. (29).

$$
w_{j}^{s}=\left(\mu_{j}-\pi_{j}\right)^{2}-\left(v_{j}-\pi_{j}\right)^{2} .
$$

Note that: If it is less than 0 , a small number is added to all criteria weights to provide a slightly greater number than zero.

Step 3.2: Normalize the aggregated criteria weights by using Eq. (30).

$$
\bar{w}_{j}^{s}=\frac{w_{j}^{s}}{\sum_{j=1}^{n} w_{j}^{s}} .
$$

Step 4: Calculate the results of Weighted Sum Model (WSM) as presented in Eq. (31).

$$
\tilde{Q}_{i}^{(1)}=\sum_{j=1}^{n} \tilde{x}_{i j w}=\sum_{j=1}^{n} \tilde{x}_{i j} \bar{w}_{j}^{s} .
$$

Eq. (31) can be divided into two parts for ease of operations. First, the multiplication operator, then the addition operator is performed.

Step 4.1: Calculate the multiplication part of Eq. (31) by using Eq. (32).

$$
\begin{aligned}
\tilde{x}_{i j w}= & \tilde{x}_{i j} \bar{w}_{j}^{s}=\left\langle\left(1-\left(1-\mu_{\tilde{x}_{i j}}^{2}\right)^{w_{j}^{s}}\right)^{1 / 2}, v_{\tilde{x}_{i j}}^{w_{j}^{s}},\right. \\
& \left.\left.\left(\left(1-\mu_{\tilde{x}_{i j}}^{2}\right)^{w_{j}^{s}}\right)-\left(1-\mu_{\tilde{x}_{i j}}^{2}-\pi_{\tilde{x}_{i j}}^{2}\right)^{w_{j}^{s}}\right)^{1 / 2}\right\rangle .
\end{aligned}
$$

Step 4.2: Calculate each addition term in Eq. (31) by using Eq. (33).

$$
\begin{aligned}
\tilde{x}_{i 1 w} \oplus \tilde{x}_{i 2 w}= & \left\langle\left(\mu_{\tilde{x}_{i 1 w}}^{2}+\mu_{\tilde{x}_{i 2 w}}^{2}-\mu_{\tilde{x}_{i 1 w}}^{2} \mu_{\tilde{x}_{i 2 w}}^{2}\right)^{1 / 2}, v_{\tilde{x}_{i 1 w}} v_{\tilde{x}_{i 2 w}},\right. \\
& \left.\left(\left(1-\mu_{\tilde{x}_{i 2 w}}^{2}\right) \pi_{\tilde{x}_{i 1 w}}^{2}+\left(1-\mu_{\tilde{x}_{i 1 w}}^{2}\right) \pi_{\tilde{x}_{i 2 w}}^{2}-\pi_{\tilde{x}_{i 1 w}}^{2} \pi_{\tilde{x}_{i 2 w}}^{2}\right)^{1 / 2}\right\rangle .
\end{aligned}
$$

Step 5: Calculate the results of Weighted Product Model (WPM) as presented in Eq. (34).

$$
\tilde{Q}_{i}^{(2)}=\prod_{j=1}^{n} \tilde{x}_{i j}^{\bar{w}^{s}} .
$$

Eq. (34) can be also divided into two parts for ease of operations. First, the exponential operator and then the multiplication operator is performed. Step 5.1: Calculate the exponential part of Eq. (34) by using Eq. (35).

$$
\tilde{x}_{i j}^{w_{j}^{s}}=\left\langle\mu_{\tilde{x}_{i j}}^{\bar{w}_{j}^{s}},\left(1-\left(1-v_{\tilde{x}_{i j}}^{2}\right)^{\bar{w}_{j}^{s}}\right)^{1 / 2},\left(\left(1-v_{\tilde{x}_{i j}}^{2}\right)^{\bar{w}_{j}^{s}}-\left(1-v_{\tilde{x}_{i j}}^{2}-\pi_{\tilde{x}_{i j}}^{2}\right)^{\bar{w}_{j}^{s}}\right)^{1 / 2}\right\rangle .
$$


Step 5.2: Calculate each multiplication term in Eq. (34) based on Eq. (36).

$$
\begin{aligned}
\tilde{x}_{i 1}^{w_{1}^{s}} \otimes \tilde{x}_{i 2}^{w_{2}^{s}}= & \left\langle\mu_{\tilde{x}_{i 1}^{w_{1}^{s}} \mu_{\tilde{x}_{i 2}^{\tilde{x}_{2}^{s}}}},\left(v_{\tilde{x}_{i 1}^{w_{1}^{s}}}^{2}+v_{\tilde{x}_{i 2}^{w_{2}^{s}}}^{2}-v_{\tilde{x}_{i 1}^{w_{1}^{s}}}^{2} v_{\tilde{x}_{i 2}^{w_{2}^{s}}}^{2}\right)^{1 / 2},\right. \\
& \left.\left(\left(1-v_{\tilde{x}_{i 2}^{s}}^{2}\right) \pi_{\tilde{x}_{i 1}^{w_{1}^{s}}}^{2}+\left(1-v_{\tilde{x}_{i 1}^{w_{1}^{s}}}^{2}\right) \pi_{\tilde{x}_{i 2}^{w_{2}^{s}}}^{2}-\pi_{\tilde{x}_{i 1}^{w_{1}^{s}}}^{2} \pi_{\tilde{x}_{i 2}^{w_{2}^{s}}}^{2}\right)^{1 / 2}\right\rangle .
\end{aligned}
$$

Step 6: Determine the threshold number $\lambda$ and calculate Eqs. (37) and (38).

$$
\begin{aligned}
& \lambda \tilde{Q}_{i}^{(1)}=\langle(1-\left.\left(1-\mu_{\tilde{Q}_{i}^{(1)}}^{2}\right)^{\lambda}\right)^{1 / 2}, v_{\tilde{Q}_{i}^{(1)}}^{\lambda},\left(\left(1-\mu_{\tilde{Q}_{i}^{(1)}}^{2}\right)^{\lambda}\right. \\
&\left.\left.-\left(1-\mu_{\tilde{Q}_{i}^{(1)}}^{2}-\pi_{\tilde{Q}_{i}^{(1)}}^{2}\right)^{\lambda}\right)^{1 / 2}\right\rangle . \\
&(1-\lambda) \tilde{Q}_{i}^{(2)}=\left\langle\left(1-\left(1-\mu_{\tilde{Q}_{i}^{(2)}}^{2}\right)^{(1-\lambda)}\right)^{1 / 2}, v_{\tilde{Q}_{i}^{(2)}}^{(1-\lambda)},\left(\left(1-\mu_{\tilde{Q}_{i}^{(2)}}^{2}\right)^{(1-\lambda)}\right.\right. \\
&\left.\left.-\left(1-\mu_{\tilde{Q}_{i}^{(2)}}^{2}-\pi_{\tilde{Q}_{i}^{(2)}}^{2}\right)^{(1-\lambda)}\right)^{1 / 2}\right\rangle .
\end{aligned}
$$

Step 7: Sum Eq. (37) and Eq. (38) as given by Eq. (39).

$$
\tilde{Q}_{i}=\lambda \tilde{Q}_{i}^{(1)}+(1-\lambda) \tilde{Q}_{i}^{(2)} .
$$

Step 8: Defuzzify by using the score function as given in Eq. (29). We put the alternatives into order with respect to the decreasing values of score values. If the score values of two alternatives are equal, their accuracy function values might be considered as in Eq. (26).

\section{An Illustrative Example}

Our proposed methodology is applied to an industrial robot selection problem. For this goal, mostly used five robots (6-axis robots X1, Scara robots X2, Dual-arm robots X3, Redundant robots X4, Cartesian robots X5) are evaluated. After a comprehensive literature review, four criteria have been determined, which are efficiency $(\mathrm{C} 1)$, suitability $(\mathrm{C} 2)$, automation (C3), and ergonomics (C4). The weights of three decision makers (DM1, DM2, DM3) having different experience levels are $0.4,0.3$ and 0.3 , respectively.

First of all, the assessments for the criteria are collected from decision makers with respect to the goal, using the linguistic terms given in Table 2. All assessments are given in Tables 4, 5, and 6.

These judgments are aggregated using SWAM operator by considering the importance levels of decision makers. Aggregated decision matrix is obtained as in Table 7.

The linguistic importance weights of the criteria assigned by DMs are shown in Table 8 .

The weight of each criterion obtained by using SWAM operator is presented in Table 9.

After the weights of the criteria have been determined, the defuzified and normalized criteria weights are calculated by utilizing Eqs. (33) and (34) as given in Table 10. 
Table 4

Assessments of DM1.

\begin{tabular}{lllll}
\hline DM1 & C1 & C2 & C3 & C4 \\
\hline X1 & AMI & SMI & VHI & SLI \\
X2 & SLI & VHI & HI & EI \\
X3 & EI & VHI & VHI & HI \\
X4 & HI & SMI & HI & EI \\
X5 & HI & HI & LI & SMI \\
\hline
\end{tabular}

Table 5

Assessments of DM2.

\begin{tabular}{lllll}
\hline DM2 & C1 & C2 & C3 & C4 \\
\hline X1 & HI & SMI & VHI & EI \\
X2 & SLI & HI & HI & HI \\
X3 & SLI & VHI & HI & EI \\
X4 & SMI & HI & LI & LI \\
X5 & HI & SMI & HI & SMI \\
\hline
\end{tabular}

Table 6

Assessments of DM3.

\begin{tabular}{lllll}
\hline DM3 & C1 & C2 & C3 & C4 \\
\hline X1 & EI & HI & HI & HI \\
X2 & VHI & EI & EI & EI \\
X3 & HI & VHI & VHI & HI \\
X4 & SMI & HI & LI & LI \\
X5 & HI & EI & EI & EI \\
\hline
\end{tabular}

Table 7

Aggregated decision matrix.

\begin{tabular}{lllll}
\hline Alternatives & C1 & C2 & C3 & C4 \\
\hline X1 & $(0.78,0.23,0.27)$ & $(0.63,0.37,0.37)$ & $(0.77,0.23,0.23)$ & $(0.55,0.46,0.40)$ \\
X2 & $(0.40,0.60,0.40)$ & $(0.71,0.30,0.32)$ & $(0.65,0.35,0.36)$ & $(0.58,0.43,0.44)$ \\
X3 & $(0.56,0.45,0.41)$ & $(0.80,0.20,0.20)$ & $(0.77,0.23,0.23)$ & $(0.65,0.35,0.36)$ \\
X4 & $(0.64,0.36,0.36)$ & $(0.66,0.34,0.34)$ & $(0.53,0.50,0.31)$ & $(0.40,0.61,0.41)$ \\
X5 & $(0.70,0.30,0.30)$ & $(0.62,0.38,0.39)$ & $(0.53,0.49,0.38)$ & $(0.57,0.43,0.43)$ \\
\hline
\end{tabular}

Table 8

Importance weights of the criteria.

\begin{tabular}{llll}
\hline Criteria & DM1 & DM2 & DM3 \\
\hline C1 & AMI & HI & EI \\
C2 & HI & LI & LI \\
C3 & VHI & VHI & HI \\
C4 & SMI & HI & HI \\
\hline
\end{tabular}

Table 9

Aggregated criteria weights.

\begin{tabular}{ll}
\hline Criteria & Weight of each criterion \\
\hline C1 & $(0.78,0.23,0.27)$ \\
C2 & $(0.53,0.50,0.31)$ \\
C3 & $(0.77,0.23,0.23)$ \\
C4 & $(0.66,0.34,0.34)$ \\
\hline
\end{tabular}


Table 10

Defuzzified and normalized criteria weights.

\begin{tabular}{ll}
\hline Criteria & Weight of each criterion \\
\hline C1 & 0.26681 \\
C2 & 0.00001 \\
C3 & 0.49129 \\
C4 & 0.24189 \\
\hline
\end{tabular}

Table 11

Weighted sum product $\left(\tilde{Q}_{i}^{(1)}\right)$.

\begin{tabular}{lll}
\hline Alternatives & $\tilde{Q}_{i}^{(1)}$ & $\lambda \tilde{Q}_{i}^{(1)}$ \\
\hline X1 & $(0.75,0.25,0.27)$ & $(0.58,0.50,0.24)$ \\
X2 & $(0.57,0.44,0.39)$ & $(0.42,0.67,0.31)$ \\
X3 & $(0.69,0.32,0.32)$ & $(0.53,0.56,0.27)$ \\
X4 & $(0.57,0.45,0.35)$ & $(0.42,0.67,0.28)$ \\
X5 & $(0.62,0.39,0.36)$ & $(0.46,0.63,0.29)$ \\
\hline
\end{tabular}

Table 12

Weighted product model $\left(\tilde{Q}_{i}^{(2)}\right)$.

\begin{tabular}{lll}
\hline Alternatives & $\tilde{Q}_{i}^{(2)}$ & $(1-\lambda) \tilde{Q}_{i}^{(2)}$ \\
\hline X1 & $(0.74,0.28,0.29)$ & $(0.57,0.53,0.25)$ \\
X2 & $(0.53,0.48,0.39)$ & $(0.39,0.69,0.31)$ \\
X3 & $(0.66,0.35,0.34)$ & $(0.50,0.59,0.29)$ \\
X4 & $(0.55,0.47,0.35)$ & $(0.40,0.69,0.28)$ \\
X5 & $(0.60,0.42,0.36)$ & $(0.45,0.65,0.30)$ \\
\hline
\end{tabular}

Table 13

$\tilde{Q}_{i}$ values.

\begin{tabular}{ll}
\hline Alternatives & $\tilde{Q}_{i}$ \\
\hline $\mathrm{X} 1$ & $(0.744,0.268,0.279)$ \\
$\mathrm{X} 2$ & $(0.548,0.463,0.392)$ \\
$\mathrm{X} 3$ & $(0.677,0.335,0.331)$ \\
$\mathrm{X} 4$ & $(0.558,0.460,0.350)$ \\
$\mathrm{X} 5$ & $(0.607,0.406,0.360)$ \\
\hline
\end{tabular}

Based on Table 9 and Eqs. (32) and (33), $\tilde{Q}_{i}^{(1)}$ is obtained as in Table 11. Based on the first column of Table 11 and Eq. (37), $\lambda \tilde{Q}_{i}^{(1)}$ is calculated as given in the second column of Table 11.

According to Table 10 and Eqs. (35) and (36), $\tilde{Q}_{i}^{(2)}$ is obtained as in Table 12. Based on the first column of Table 12 and Eq. $(38),(1-\lambda) \tilde{Q}_{i}^{(2)}$ is calculated as given in the second column of Table 12 .

In the next step, based on Tables 11 and 12, we can calculate the final value of SFWASPAS using Eq. (39). They are given in Table 13.

From Table 13, the score value of each alternative is calculated based on Eq. (29) and given in Table 14. 
Table 14

Score values and ranking.

\begin{tabular}{lll}
\hline Alternatives & Score & Ranking \\
\hline X1 & 0.217 & 1 \\
X2 & 0.019 & 5 \\
X3 & 0.120 & 2 \\
X4 & 0.031 & 4 \\
X5 & 0.059 & 3 \\
\hline
\end{tabular}

Table 15

IF linguistic scale (Boran et al., 2009).

\begin{tabular}{ll}
\hline Linguistic terms & $(\mu, \nu, \pi)$ \\
\hline Absolutely more Importance (AMI) & $(0.9,0.1,0)$ \\
Very High Importance (VHI) & $(0.8,0.1,0.1)$ \\
High Importance (HI) & $(0.7,0.2,0.1)$ \\
Slightly More Importance (SMI) & $(0.6,0.3,0.1)$ \\
Equally Importance (EI) & $(0.5,0.4,0.1)$ \\
Slightly Low Importance (SLI) & $(0.4,0.5,0.1)$ \\
Low Importance (LI) & $(0.25,0.6,0.15)$ \\
Very Low Importance (VLI) & $(0.1,0.75,0.15)$ \\
Absolutely Low Importance (ALI) & $(0.1,0.9,0)$ \\
\hline
\end{tabular}

The score values indicate that the best alternative is $\mathrm{X} 1$ and overall ranking is $X 1>$ $X 3>X 5>X 4>X 2$.

\section{Comparative and Sensitivity Analyses}

We compare the proposed SF-WASPAS with intuitionistic fuzzy TOPSIS (IF-TOPSIS) in this section. Table 15 presents the IF linguistic scale, which we use for comparison purposes.

In this comparison, the same judgments as given in Tables 4, 5 and 6 were used and aggregated using IFWA (Intuitionistic Fuzzy Weighted Average) operator given in Eq. (40) (Xu, 2007). Aggregated decision matrix is given in Table 16.

$$
\begin{aligned}
\operatorname{IFWA}\left(r_{i j}\right) & =\lambda_{1} r_{i j}^{(1)} \oplus \lambda_{2} r_{i j}^{(2)} \oplus \cdots \oplus \lambda_{l} r_{i j}^{(l)} \\
& =\left[1-\prod_{k=1}^{l}\left(1-\mu_{i j}^{k}\right)^{\lambda_{k}}, \prod_{k=1}^{l}\left(v_{i j}^{k}\right)^{\lambda_{k}}, \prod_{k=1}^{l}\left(1-\mu_{i j}^{k}\right)^{\lambda_{k}}+\prod_{k=1}^{l}\left(v_{i j}^{k}\right)^{\lambda_{k}}\right] .
\end{aligned}
$$

The same criteria judgments given in Table 8 are used for this comparison. Opinions of decision makers on criteria are aggregated using IFWA operator and the weight of each criterion is presented in Table 17. 
Table 16

Aggregated decision matrix.

\begin{tabular}{lllll}
\hline Alternatives & C1 & C2 & C3 & C4 \\
\hline X1 & $(0.77,0.19,0.04)$ & $(0.70,0.20,0.10)$ & $(0.81,0.15,0.03)$ & $(0.80,0.17,0.03)$ \\
X2 & $(0.57,0.31,0.12)$ & $(0.72,0.20,0.08)$ & $(0.73,0.16,0.11)$ & $(0.45,0.45,0.10)$ \\
X3 & $(0.55,0.35,0.11)$ & $(0.49,0.39,0.12)$ & $(0.73,0.16,0.11)$ & $(0.45,0.42,0.13)$ \\
X4 & $(0.64,0.26,0.10)$ & $(0.61,0.28,0.12)$ & $(0.61,0.24,0.14)$ & $(0.61,0.28,0.11)$ \\
X5 & $(0.70,0.20,0.10)$ & $(0.62,0.28,0.10)$ & $(0.50,0.38,0.12)$ & $(0.57,0.33,0.10)$ \\
\hline
\end{tabular}

Table 17

Aggregated criteria matrix.

\begin{tabular}{cc}
\hline Criteria & Weight of each criterion \\
\hline C1 & $(0.77,0.19,0.04)$ \\
C2 & $(0.48,0.39,0.13)$ \\
C3 & $(0.77,0.12,0.10)$ \\
C4 & $(0.66,0.24,0.10)$ \\
\hline
\end{tabular}

Table 18

Aggregated weighted decision matrix.

\begin{tabular}{lllll}
\hline Alternatives & C1 & C2 & C3 & C4 \\
\hline X1 & $(0.60,0.34,0.06)$ & $(0.30,0.55,0.15)$ & $(0.60,0.23,0.17)$ & $(0.36,0.51,0.14)$ \\
X2 & $(0.44,0.44,0.12)$ & $(0.34,0.50,0.16)$ & $(0.50,0.34,0.16)$ & $(0.38,0.48,0.14)$ \\
X3 & $(0.42,0.47,0.11)$ & $(0.38,0.45,0.17)$ & $(0.60,0.23,0.17)$ & $(0.43,0.42,0.15)$ \\
X4 & $(0.50,0.39,0.11)$ & $(0.32,0.53,0.15)$ & $(0.37,0.46,0.17)$ & $(0.24,0.63,0.13)$ \\
X4 & $(0.54,0.35,0.11)$ & $(0.30,0.56,0.15)$ & $(0.38,0.46,0.16)$ & $(0.38,0.49,0.13)$ \\
\hline
\end{tabular}

After the weights of the criteria and the rating of the alternatives have been determined, the aggregated weighted intuitionistic fuzzy decision matrices are constructed by utilizing Eqs. (41) and (42) as given in Table 18.

$$
\tilde{A} \otimes \tilde{B}=\left\langle\mu_{\tilde{A}} \mu_{\tilde{B}}, v_{\tilde{A}}+v_{\tilde{B}}-v_{\tilde{A}} v_{\tilde{B}}\right\rangle
$$

and

$$
\pi_{\tilde{A} \tilde{B}}=1-\mu_{\tilde{A}} \mu_{\tilde{B}}-v_{\tilde{A}}-v_{\tilde{B}}+v_{\tilde{A}} v_{\tilde{B}}
$$

Positive and negative ideal solutions are given in Table 19. They are calculated by using Eqs. (43) and (44).

$$
\begin{aligned}
& X^{*}=\left(\max _{i} \mu_{X_{i} w}\left(C_{j}\right), \min _{i} v_{X_{i} w}\left(C_{j}\right)\right), \\
& X^{-}=\left(\min _{i} \mu_{X_{i} w}\left(C_{j}\right), \max _{i} v_{X_{i} w}\left(C_{j}\right)\right) .
\end{aligned}
$$


Table 19

Positive and negative ideal solutions.

\begin{tabular}{lllll}
\hline & $\mathrm{C} 1$ & $\mathrm{C} 2$ & $\mathrm{C} 3$ & $\mathrm{C} 4$ \\
\hline $\mathrm{X}^{*}$ (Best) & $(0.60,0.34,0.06)$ & $(0.38,0.45,0.17)$ & $(0.60,0.23,0.17)$ & $(0.43,0.42,0.15)$ \\
$\mathrm{X}$ (Worst) & $(0.42,0.47,0.11)$ & $(0.30,0.55,0.15)$ & $(0.37,0.46,0.17)$ & $(0.24,0.63,0.13)$ \\
\hline
\end{tabular}

Table 20

Distances to positive and negative ideal solutions.

\begin{tabular}{lll}
\hline Alternatives & $D_{E}\left(X_{i}, X^{*}\right)$ & $D_{E}\left(X_{i}, X^{-}\right)$ \\
\hline X1 & 0.061 & 0.151 \\
X2 & 0.095 & 0.098 \\
X3 & 0.079 & 0.158 \\
X4 & 0.162 & 0.038 \\
X5 & 0.128 & 0.092 \\
\hline
\end{tabular}

Table 21

Closeness ratio of each alternative.

\begin{tabular}{lll}
\hline Alternatives & Closeness ratio & Ranking \\
\hline X1 & 0.713 & 1 \\
X2 & 0.509 & 3 \\
X3 & 0.666 & 2 \\
X4 & 0.192 & 5 \\
X5 & 0.419 & 4 \\
\hline
\end{tabular}

Based on Eq. (45), we can calculate the Euclidean distances between alternative $X_{i}$ and SF-PIS as well as $X_{i}$ and SF-NIS. They are given in Table 20 (Szmidt and Kacprzyk, 2000).

$$
D_{E}\left(X_{i}, X^{-,+}\right)=\sqrt{\frac{\sum_{1}^{n}\left(\left(\mu_{x_{i}}-\mu_{x^{-,+}}\right)^{2}+\left(v_{x_{i}}-v_{x^{-,+}}\right)^{2}+\left(\pi_{x_{i}}-\pi_{x^{-,+}}\right)^{2}\right)}{2 n}} .
$$

Closeness ratios are calculated based on Eq. (46) and presented in Table 21.

$$
\xi\left(X_{i}\right)=\frac{D_{E}\left(X_{i}, X^{-}\right)}{D_{E}\left(X_{i}, X^{-}\right)+D_{E}\left(X_{i}, X^{+}\right)} .
$$

The closeness ratios based on IF-TOPSIS method indicate that the best alternative is $\mathrm{X} 1$ and the overall ranking is $X 1>X 3>X 2>X 5>X 4$. Table 22 presents the ranking of the alternatives according to the IF-TOPSIS and SF-WASPAS methods. We can say that the first alternative should be selected among the industrial robot alternatives.

We applied a sensitivity analysis by changing the threshold number $\lambda$ and observed the robustness of the given decisions. Sensitivity analysis showed that very robust decisions have been obtained from SF-WASPAS as given in Fig. 7. Although the appraisal scores changed, the ranking of alternatives remained the same. 
Table 22

Ranking of the alternatives.

\begin{tabular}{lll}
\hline Alternatives & IF-TOPSIS & SF-WASPAS \\
\hline X1 & 1 & 1 \\
X2 & 5 & 3 \\
X3 & 2 & 2 \\
X4 & 4 & 5 \\
X5 & 3 & 4 \\
\hline
\end{tabular}

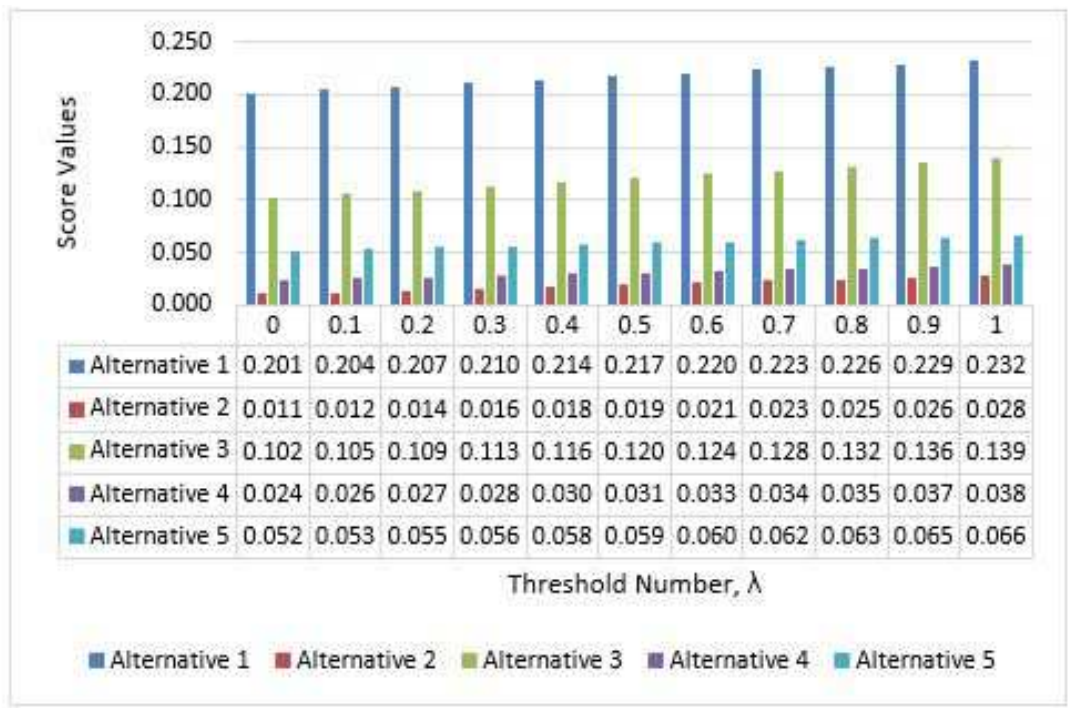

Fig. 7. Sensitivity analysis by changing threshold value, $\lambda$.

\section{Conclusion and Future Work}

Three dimensional membership functions have been very popular in the recent years. IFS, PFS, and NS use those kinds of membership functions. Spherical fuzzy sets are an attempt to provide a general view to three dimensional fuzzy sets. We presented the theory of spherical fuzzy sets (SFS) and their arithmetic operations in this paper together with their aggregation operators. This new type of fuzzy sets has been used in the extension of WASPAS to SF-WASPAS, which is a weighted combination of WSM and WPM methods. In SF-WASPAS, spherical fuzzy sets have been used in all of the steps without making any defuzzification, except the calculation of the weights of the criteria. Through the proposed SF-WASPAS, DMs could assign their judgments on the membership, non-membership and hesitancy degrees as independent parameters under spherical fuzzy uncertainty environment.

An industrial robot selection problem has been successfully solved by SF-WASPAS and compared with IF-TOPSIS. Comparative analysis with IF-TOPSIS showed the validity of the obtained results by SF-WASPAS with slight changes. Additionally, we applied a 
sensitivity analysis by changing threshold value $(\lambda)$ and observed the robustness of the given decisions. Sensitivity analysis showed that very robust decisions have been obtained from SF-WASPAS.

For further research, we suggest SF-WASPAS to be compared with other extensions of MCDM methods such as SF-CODAS, SF-TOPSIS, SF-AHP and SF-VIKOR.

\section{References}

Atanassov, K.T. (1986). Intuitionistic fuzzy sets. Fuzzy sets and Systems, 20(1), 87-96.

Atanassov, K.T. (1999). Other Extensions of Intuitionistic Fuzzy Sets. Physica, Heidelberg, pp. 179-198.

Bausys, R., Juodagalviene, B. (2017). Garage location selection for residential house by WASPAS-SVNS method. Journal of Civil Engineering and Management, 23(3), 421-429.

Boran, F.E., Genc, S., Kurt, M., Akay, D. (2009). A multi-criteria intuitionistic fuzzy group decision making for supplier selection with TOPSIS method. Expert Systems with Applications, 36(8), 11363-11368.

Can, G.F. (2018). An intutionistic approach based on failure mode and effect analysis for prioritizing corrective and preventive strategies. Human Factors and Ergonomics in Manufacturing and Service Industries, 28(3), $130-147$.

Chakraborty, S., Zavadskas, E.K. (2014). Applications of WASPAS method in manufacturing decision making. Informatica, 25(1), 1-20.

Cheng, S.H., Chen, S.M., Huang, Z.C. (2016). Autocratic decision making using group recommendations based on ranking interval type-2 fuzzy sets. Information Sciences, 361, 135-161.

Chen, S.M., Chang, C H. (2016). Fuzzy multiattribute decision making based on transformation techniques of intuitionistic fuzzy values and intuitionistic fuzzy geometric averaging operators. Information Sciences, 352, 133-149.

Chen, J., Wang, J., Balezentis, T., Zagurskaite, F., Streimikiene, D., Makuteniene, D. (2018). Multicriteria approach towards the sustainable selection of a teahouse location with sensitivity analysis. Sustainability, 10(8), 2926.

Chiao, K.P. (2016). The multi-criteria group decision making methodology using type 2 fuzzy linguistic judgments. Applied Soft Computing, 49, 189-211.

Dejus, T., Antucheviciene, J. (2013). Assessment of health and safety solutions at a construction site. Journal of Civil Engineering and Management, 19(5), 728-737.

Garibaldi, J.M., Ozen, T. (2007). Uncertain fuzzy reasoning: a case study in modelling expert decision making. IEEE Transactions on Fuzzy Systems, 15(1), 16-30.

Garg, H. (2016). A novel correlation coefficients between Pythagorean fuzzy sets and its applications to decisionmaking processes. International Journal of Intelligent Systems, 31(12), 1234-1252.

Grattan Guinness, I. (1976). Fuzzy membership mapped onto intervals and many valued quantities. Mathematical Logic Quarterly, 22(1), 149-160.

Gong, Z., Xu, X., Yang, Y., Zhou, Y., Zhang, H. (2016). The spherical distance for intuitionistic fuzzy sets and its application in decision analysis. Technological and Economic Development of Economy, 22(3), 393-415.

Hafezalkotob, A., Hami-Dindar, A., Rabie, N., Hafezalkotob, A. (2018). A decision support system for agricultural machines and equipment selection: a case study on olive harvester machines. Computers and Electronics in Agriculture, 148, 207-216.

He, Y., He, Z., Shi, L., Meng, S. (2016). Multiple attribute group decision making based on IVHFPBMs and a new ranking method for interval-valued hesitant fuzzy information. Computers and Industrial Engineering, 99, 63-77.

Jahan, A. (2018). Developing WASPAS-RTB method for range target-based criteria: toward selection for robust design. Technological and Economic Development of Economy, 24(4), 1362-1387.

Keshavarz Ghorabaee, M., Zavadskas, E.K., Amiri, M., Esmaeili, A. (2016). Multi-criteria evaluation of green suppliers using an extended WASPAS method with interval type-2 fuzzy sets. Journal of Cleaner Production, 137, 213-229.

Keshavarz Ghorabaee, M., Amiri, M., Zavadskas, E.K., Antucheviciene, J. (2017). Assessment of third-party logistics providers using a CRITIC-WASPAS approach with interval type-2 fuzzy sets. Transport, 32(1), $66-78$. 
Kutlu Gundogdu, F., Kahraman, C. (2018). Spherical fuzzy sets and spherical fuzzy TOPSIS method. Journal of Intelligent and Fuzzy Systems, 1-16.

Kutlu Gundogdu, F., Kahraman, C., Civan, H.N. (2018). A novel hesitant fuzzy EDAS method and its application to hospital selection. Journal of Intelligent and Fuzzy Systems, 1-13.

Lashgari, S., Antucheviciene, J., Delavari, A., Kheirkhah, O. (2014). Using QSPM and WASPAS methods for determining outsourcing strategies. Journal of Business Economics and Management, 15(4), 729-743.

Liu, P. (2016). The aggregation operators based on archimedean t-Conorm and t-Norm for single-valued neutrosophic numbers and their application to decision making. International Journal of Fuzzy Systems, 5, 849863.

Liu, P., Zhang, L., Liu, X., Wang, P. (2016). Multi-valued neutrosophic number Bonferroni mean operators with their applications in multiple attribute group decision making. International Journal of Information Technology and Decision Making, 15(05), 1181-1210.

Liu, Z., Liu, P., Liu, W., Pang, J. (2017). Pythagorean uncertain linguistic partitioned Bonferroni mean operators and their application in multi-attribute decision making. Journal of Intelligent and Fuzzy Systems, 32(3), 2779-2790.

Ma, H., Hu, Z., Li, K., Zhang, H. (2016). Toward trustworthy cloud service selection: a time-aware approach using interval neutrosophic set. Journal of Parallel and Distributed Computing, 96, 75-94.

Mishra, A.R., Singh, R.K., Motwani, D. (2018). Multi-criteria assessment of cellular mobile telephone service providers using intuitionistic fuzzy WASPAS method with similarity measures. Granular Computing, 1-19.

Nie, R.X., Wang, J.Q., Zhang, H.Y. (2017). Solving solar-wind power station location problem using an extended weighted aggregated sum product assessment (WASPAS) technique with interval neutrosophic sets. Symmetry, 9(7), 106.

Qin, J., Liu, X., Pedrycz, W. (2016). Frank aggregation operators and their application to hesitant fuzzy multiple attribute decision making. Applied Soft Computing, 41, 428-452.

Peng, X., Yang, Y. (2016). Pythagorean fuzzy choquet integral based MABAC method for multiple attribute group decision making. International Journal of Intelligent Systems, 31(10), 989-1020.

Peng, X., Dai, J. (2017). Hesitant fuzzy soft decision making methods based on WASPAS, MABAC and COPRAS with combined weights. Journal of Intelligent and Fuzzy Systems, 33(2), 1313-1325.

Ren, P., Xu, Z., Gou, X. (2016). Pythagorean fuzzy TODIM approach to multi-criteria decision making. Applied Soft Computing, 42, 246-259.

Sambuc, R. (1975). Fonctions and Floues: Application a l'aide au Diagnostic en Pathologie Thyroidienne. Faculté de Médecine de Marseille.

Smarandache, F. (1998). Neutrosophy: Neutrosophic Probability, Set, and Logic: Analytic Synthesis \& Synthetic Analysis.

Stojic, G., Stevic, Z., Antucheviciene, J., Pamucar, D., Vasiljevic, M. (2018). A novel rough WASPAS approach for supplier selection in a company manufacturing PVC carpentry products. Information, 9(5), 121.

Stevic, Z., Pamucar, D., Subotic, M., Antucheviciene, J., Zavadskas, E. (2018). The location selection for roundabout construction using rough BWM-rough WASPAS approach based on a new rough hamy aggregator. Sustainability, 10(8), 2817.

Szmidt, E., Kacprzyk, J. (2000). Distances between intuitionistic fuzzy sets. Fuzzy sets and systems, 114(3), $505-518$.

Turskis, Z., Zavadskas, E.K., Antucheviciene, J., Kosareva, N. (2015). A hybrid model based on fuzzy AHP and fuzzy WASPAS for construction site selection. International Journal of Computers Communications \& Control, 10(6), 113-128.

Torra, V. (2010). Hesitant fuzzy sets. International Journal of Intelligent Systems, 25(6), 529-539.

Vafaeipour, M., Zolfani, S.H., Varzandeh, M.H.M., Derakhti, A., Eshkalag, M.K. (2014). Assessment of regions priority for implementation of solar projects in Iran: new application of a hybrid multi-criteria decision making approach. Energy Conversion and Management, 86, 653-663.

Xu, G.L., Wan, S.P., Wang, F., Dong, J.Y., Zeng, Y.F. (2016). Mathematical programming methods for consistency and consensus in group decision making with intuitionistic fuzzy preference relations. KnowledgeBased Systems, 98, 30-43.

Xu, Z. (2007). Intuitionistic fuzzy aggregation operators. IEEE Transactions on Fuzzy Systems, 15(6), 11791187.

Yager, R.R. (1986). On the theory of bags. International Journal of General System, 13(1), 23-37.

Yager, R.R. (2013). Pythagorean fuzzy subsets. In: IFSA World Congress and NAFIPS Annual Meeting (IFSA/NAFIPS), pp. 57-61. 
Yager, R.R. (2017). Generalized orthopair fuzzy sets. IEEE Transactions on Fuzzy Systems, 25(5), 1222-1230.

Yang, Y., Chiclana, F. (2009). Intuitionistic fuzzy sets: Spherical representation and distances. International Journal of Intelligent Systems, 24(4), 399-420.

$\mathrm{Yu}, \mathrm{S}$., Xu, Z. (2016). Definite integrals of multiplicative intuitionistic fuzzy information in decision making. Knowledge-Based Systems, 100, 59-73.

Zadeh, L.A. (1965). Fuzzy sets. Information and Control, 8(3), 338-353.

Zadeh, L.A. (1975). The concept of a linguistic variable and its application to approximate reasoning - I. Information Sciences, 8(3), 199-249.

Zavadskas, E.K., Turskis, Z., Antucheviciene, J., Zakarevicius, A. (2012). Optimization of weighted aggregated sum product assessment. Elektronika ir elektrotechnika, 122(6), 3-6.

Zavadskas, E.K., Antucheviciene, J., Hajiagha, S.H.R., Hashemi, S.S. (2014). Extension of weighted aggregated sum product assessment with interval-valued intuitionistic fuzzy numbers (WASPAS-IVIF). Applied Soft Computing, 24, 1013-1021.

Zavadskas, E.K., Chakraborty, S., Bhattacharyya, O., Antucheviciene, J. (2015a). Application of WASPAS method as an optimization tool in non-traditional machining processes. Information Technology and Control, 44(1), 77-88.

Zavadskas, E.K., Turskis, Z., Antucheviciene, J. (2015b). Selecting a contractor by using a novel method for multiple attribute analysis: Weighted Aggregated Sum Product Assessment with grey values (WASPAS-G). Studies in Informatics and Control, 24(2), 141-150.

Zavadskas, E.K., Chakraborty, S., Bhattacharyya, O., Antucheviciene, J. (2015c). Application of WASPAS method as an optimization tool in non-traditional machining processes. Information Technology and Control, 44(1), 77-88.

Zavadskas, E.K., Kalibatas, D., Kalibatiene, D. (2016). A multi-attribute assessment using WASPAS for choosing an optimal indoor environment. Archives of Civil and Mechanical Engineering, 16(1), 76-85. 
F. Kutlu Gundogdu is a research assistant at Istanbul Kultur University in the Industrial Engineering Department. Her research areas are quality control and management, statistical decision-making, multi-criteria decision-making, spherical fuzzy sets, fuzzy optimization and fuzzy decision-making. She published some journal papers and conference papers in the mentioned fields. She is the referee of some international journals.

C. Kahraman is a full professor at Istanbul Technical University. His research areas are engineering economics, quality control and management, statistical decision-making, multi-criteria decision-making and fuzzy decision making. He published about 2420 journal papers and about 160 conference papers. He became the guest editor of many international journals and the editor of many international books from Springer and Atlantis Press. He is the member of editorial boards of 20 international journals. He organized various international conferences. He was the vice dean of ITU Management Faculty between 2004-2007 and the head of ITU Industrial Engineering Department between 2010-2013. 